\author{
$n^{\circ}$ 2011-19 \\ Place-based Tax Exemptions \\ and Displacement Effects : \\ An Evaluation of the Zones \\ Franches Urbaines Program \\ P. GIVORD ${ }^{1}$ - R. RATHELOT ${ }^{2}$ \\ P. SILLARD ${ }^{3}$
}

Les documents de travail ne reflètent pas la position du CREST et n'engagent que leurs auteurs. Working papers do not reflect the position of CREST but only the views of the authors.

\footnotetext{
1 CREST (INSEE), pauline.givord@insee.fr

2 CREST, roland.rathelot@ensae.fr (Corresponding author : CREST, 15 boulevard Gabriel Péri, 92245 Malakoff cedex, France. Tel. : +33 1411760 36, Fax : +33 1411760 29).

3 CREST (INSEE), patrick.sillard@insee.fr
} 


\title{
Place-Based Tax Exemptions and Displacement Effects: An Evaluation of the Zones Franches Urbaines Program*
}

\author{
Pauline GIVORD $^{\dagger}$ Roland RATHELOT ${ }^{\ddagger}$ Patrick SILlARD ${ }^{\S}$
}

July 13, 2011

\begin{abstract}
We propose to evaluate the impact of the French Zones Franches Urbaines on economic activity. This public-funded place-based program, comparable to US enterprise zones, exempts new and existing firms from taxes for a period of at least 5 years. For the purpose of this evaluation, we merged several administrative datasets at the firmlevel. This allows us to exhaustively observe business creations and stocks, as well as employment and financial outcomes for each firm at a precise geographical level. We focus on the second wave of the program, during which treated territories were selected among a pool of deprived territories according to a known set of covariates. The way treatment was assigned makes the conditional independence assumption credible in our case. Overall, we find significant effects on business creation and on employment while the effect on firms that were located in the treated areas before the program is not significant, regardless of the outcome. Finally, we provide evidence of significant negative spillovers of the program on neighboring areas.
\end{abstract}

Keywords: enterprise zone, local employment, place-based policies, propensity score matching, externalities.

JEL: C23, J23, R38

${ }^{*}$ We thank Yoann Barbesol, Virginie Régnier and Simon Quantin for their help in processing the data, Raphaël Janelli for providing us with the maps and Luc Behaghel, Didier Blanchet, Anthony Briant, Thomas Le Barbanchon, Sébastien Roux, Jean-François Royer, Hélène Thélot as well as participants of seminars at INSEE, Paris 13 University, Ministry of Labor, Rencontres du Logement and ESPE conferences for useful comments and discussions. The opinions expressed here are those of the authors and not of any institution.

${ }^{\dagger}$ CREST(INSEE), pauline.givord@insee.fr

${ }^{\ddagger}$ CREST, roland.rathelot@ensae.fr, Corresponding author, CREST - Bâtiment MK2 Bureau 2020 - 15

Boulevard Gabriel Péri - 92245 Malakoff Cedex - France - Tel. : +33141176036 - Fax. : +33141176029

${ }^{\S}$ CREST(INSEE), patrick.sillard@insee.fr 


\section{Introduction}

The long-standing debate regarding the appropriate remedy to the deteriorating conditions in urban areas with high levels of poverty and unemployment remains open. As emphasized in the literature review proposed by Hellerstein \& Neumark (2011), policy-makers have tried many approaches to strive against unemployment in these areas. Bringing back jobs to deprived areas, relocating people where jobs are, or improving transportation systems all aim to decrease the potential spatial mismatch between employers and employees. While people-relocation policies are believed to have been unable, at a large scale, to improve labor market conditions of the populations living in the poorest neighborhoods, ${ }^{1}$ there is no indisputable conclusion concerning job-relocation or transportation policies. In this paper, we provide one more piece of evidence to the vast literature about the effectiveness of geographically-targeted tax exemptions. We focus on the evaluation of the French Zones Franches Urbaines (ZFU) program, which aimed, through placed-based tax exemptions, to boost business creations/relocations therefore employment rates in a few targeted deprived areas.

In France, sporadic outbursts of violence (the 2005 riots being the last example) have indeed called for revitalizing policies in poor suburban areas (often referred to as the "Banlieue") characterized by a high concentration of social problems. Since the end of the 90s, French policy-makers have tried several programs targeting these economically distressed neighborhoods. ${ }^{2}$ The ZFU are by far the most ambitious program, at least as regards the amount of public fundings. Being located within the limits of a ZFU allows a firm to be totally exempted from business and corporate taxes as well as social security contributions. The goal is obviously to encourage businesses to locate or to avoid leaving these areas. This system is particularly expensive, with a loss of tax and social security contributions for the State estimated at $€ 70$ million for the sole year of 2006 , what calls for a thorough evaluation of its effects.

While several articles show that spatial mismatch may explain a large part of urban unemployment. $^{3}$, there is no consensus in the evaluation literature on whether place-based

\footnotetext{
${ }^{1}$ See e.g. Rosenbaum \& Zuberi (2010) for an overview of the findings of the evaluations of Gautreaux and Moving-To-Opportunity programs.

${ }^{2}$ In what follows, a neighborhood has typically a population of 9,000 to 30,000 .

${ }^{3}$ Using a Swedish dispersal policy of refugees, Åslund et al. (2010) provide evidence that being located further from jobs adversely affects employment probability In the case of France, Gobillon et al. (2011) show that spatial differences contributes to explain more than half of the differences of individual unemployment spell durations. See Gobillon et al. (2007) for a review about spatial mismatch.
} 
tax exemptions are efficient to lure business in distressed areas and improve local labor market conditions. The major part of the empirical evaluation literature finds that US Enterprise Zones have little or no impact on economic activity and employment (Bondonio \& Greenbaum 2007, Neumark \& Kolko 2010), while Busso \& Kline (2008) provide evidence in the opposite direction for federal-level Empowerment Zones. ${ }^{4}$ In a recent contribution, Ham et al. (2011) re-examine all US programs for a wider set of outcomes and find more encouraging results for place-based policies. As Hellerstein \& Neumark (2011) put it, most existing evaluations face two kinds of issues. First, as EZ borders do not necessarily follow administrative borders, a significant fraction of the area considered as treated in most studies is not actually treated. This measurement error is likely to bias downwards the estimator of the impact. Second, the issue of which areas are considered as a valid control group is of paramount importance. Because of the quality of the data we use and because of the selection process of the ZFU, we argue that our paper brings a contribution to the international debate about place-based tax-exemption policies. From a national point of view, our paper is also the first to evaluate the impact of the French program on economic activity. $^{5}$

We use exhaustive administrative panel establishment-level data with precise location for the period 2002-2007. We know when each establishment is created, whether this creation is a new business or a relocation, and when it failed. For each year, we also know how many employees work in the establishment, their wages, as well as several outcomes regarding the firm's economic and financial health (income, sales, cash flow, debt, investment). Therefore, we can measure the impact of the program on business entry and exit rates, economic activity, employment, as well as on firms' financial strength. We are also able to differentiate firms that settled before and after the implementation of the program. The decisive advantage of our data is the access to precise location of each establishment. This is interesting as, like EZ in the US, ZFU borders do not coincide with the ones of preexisting jurisdictions. We thus know here with certainty whether a given firm is located within or beyond the boundaries delimiting tax exemption. ${ }^{6}$

The implementation of the ZFU program occurred in three waves, respectively in 1997, 2004 and 2006. In this paper, we focus on the second wave as it has several desirable fea-

\footnotetext{
${ }^{4}$ The controversy also involve Bondonio \& Engberg (2000), Greenbaum \& Bondonio (2004), Elvery (2009) or Lynch \& Zax (2010) that find no effect and Papke (1994), O'Keefe (2004) that do.

${ }^{5}$ Gobillon et al. (2010) provide a complementary analysis on the impact of ZFU on local unemployment. They use public-employment-service data, at the level of municipalities, and find that the first wave of ZFU brought about a very small drop of the number of job seeker in treated areas.

${ }^{6}$ Before us, to our knowledge, only Neumark \& Kolko (2010) use data at such a precise scale.
} 
tures for evaluation. In 1997, when the government defined the 44 territories that would be granted the ZFU status for the first wave, 416 other territories were also labeled Zones de Redynamisation Urbaine (ZRU). The difference between the two programs, in terms of the generosity of the exemptions is very large (see infra for details). Supposedly, the 44 first-wave ZFU were the most distressed areas, while the 416 ZRU would be slightly less distressed. In 2004, 41 new ZFU were created - all chosen within the pool of the ZRU. Our main strategy consists in comparing outcomes between ZRUs that became ZFU and ZRUs that remained ZRU by propensity score matching. Of course, such a strategy has to deal with selection bias. As ZFU are supposed to be more economically depressed than ZRU, firms may naturally choose to locate less often in ZFU, regardless of the tax incentive. This would induce a negative selection bias on the impact of the program.

In practice, two elements may be argued in favor of our strategy. First, the most distressed neighborhoods, which might have been really difficult to compare, were turned into ZFU in the first wave of the program. Statistical evidence shows that first-wave ZFU are strikingly more distressed than second-wave ones. Second, the committee in charge of choosing which ZRU would be granted ZFU status in 2004 was supposed to follow precise guidelines: an index calculated using five local variables (total population, unemployment rate, tax revenues, proportion of youth, proportion of dropouts) should have driven their choice. As we were also able to compute these variables and this index, we find that the ZRU chosen to become ZFU were actually not so different from the ones that areas that do not benefit from the policy. As the summary statistics and propensity score estimation make clear, the most crucial factor that determined which areas were selected in the second wave was their location: an area had more chance to be chosen if it was further from a first-wave ZFU and closer to another ZRU. ${ }^{7}$

We find that tax exemptions provided by the ZFU program had a positive impact on the number of firms located in the treated areas. Such impact is mainly driven by an increase in the number of new firms, both births and relocations. In relative terms though, the increase is mainly due to a surge in the number of firms relocating. The program also had an impact on total employment in the area, both measured in jobs and worked hours. However, the program does not seem to have an effect whatsoever on establishments that already existed in 2002. While these existing firms were as eligible as new ones to tax exemptions, their survival rate, their employment level, as well as their economic situation

\footnotetext{
${ }^{7}$ This is consistent with anecdotal evidence that suggest that, as local authorities pressured the government to benefit from ZFU fundings, an implicit criterion for selection in the second-wave was to make sure that all regions had its own ZFU.
} 
were essentially unaffected by the program.

While the main analysis makes use of the pool of ZRU to obtain a causal effect of the program, our data make it possible to assess the impact of the program not only on the treated areas but also on their neighborhoods. Place-based policies are often blamed for "cannibalizing" neighboring communities by causing a shift of economic activity within a city, from areas that do not benefit from the program to areas that do. It is obviously an important concern for public policy to know whether a revitalizing program spurs the development of one area at the expense of another. We build a 300-meter rings around the ZFUs and untreated areas and use the latter as controls for the former. We find that the ZFU program had significant negative spillover effects at least during the first three years, in the areas just beyond the ZFU boundary. Negative effects are observed on economic activity outcomes (number of establishments, creation rates...) but not on employment outcomes. Spillovers have, on average, the same order of magnitude as the impact of the program, which means that the positive impact on treated areas is likely to be totally offset by negative impacts on their immediate vicinity.

The following section introduces the institutional contexts and the features of the evaluated program. Section 3 presents the data as well as some summary statistics. In section 4, we detail the methodology used. The results of the estimations - both the direct impact of the policy and some evidence about displacement effects - are spelled out in section 5 . Finally, in the last section, the main results are wrapped up and discussed under a policy perspective.

\section{A brief description of the French Enterprise Zones}

Since the early 1980s, the deterioration of economic and social conditions in a growing number of suburban neighborhoods has led the French government to take a series of measures, generically named Politique de la Ville (Urban Policy). The common features of these neighborhoods are higher unemployment and poverty rates, a limited access to public services and to retail as well as relatively low property prices. The first two development stages of French urban policy in the 1980s and early 1990s have not been evaluated. Anyway, in many distressed neighborhoods, they have not been enough to solve issues.

The Pacte de Relance de la Ville (Urban Revival Pact), initiated in 1996, constitutes the third stage. Stressing the need for economic revival in sensitive urban areas (ZUS) as a prerequisite for their social renovation, the pact lists several hundreds of priority neigh- 
borhoods and grants them tax exemptions to attract new business and raise employment. Three categories are created. First, 750 neighborhoods are labeled as Zones Urbaines Sensibles (ZUS). In practice, being a ZUS alone does not grant any kind of tax exemptions, but rather signal that local money should go there in priority. Then, 416 particularly distressed ZUS neighborhoods are declared Zones de Revitalisation Urbaine (ZRU), while the 44 most underprivileged are assigned to the ZFU program. In contrast to ZUS, firms entering a ZRU or a ZFU are entitled to tax rebates and exemptions.

The objective of the ZFU (and ZRU) programs is to promote the economic development of these areas. These programs grant substantial tax relief to existing and new businesses, with a much higher exemption level in ZFUs than ZRUs (see Appendix A for details). Companies with less than 50 employees benefit, for their establishments located in ZFUs, from five-year exemptions from local business tax, corporate income tax and property tax. Employer contributions are also exempt for five years on the fraction of salary lower than 1.4 times the minimum wage. This aid is limited and the system terminates over a progressive 3 to 9 year period subsequent to the full-rate exemption period of the first five years (see the appendix). 10 years after its entry in the program, a firm with less than five employees still benefit from a $60 \%$ tax rebate. Moreover, in practice, all ZFUs were postponed beyond the theoretical deadline and are active as of today.

The second wave of ZFU creations occurred in January 2004, with 41 new ZFUs. These areas were selected out of the existing ZRUs. Officially, the selection criterion is specified by a decree as a combination of 5 local indicators, namely the total population of the area, the unemployment rate, the proportion of youth (under 25), the proportion of drop-outs with no qualification and the tax potential of the municipality. ${ }^{8}$ The composite index is calculated as the product of the first four elements, divided by the fifth. In addition, it is specified that a ZFU should have more than 10,000 residents. The geographical extent of a ZFU can be flexible in order to meet this last criterion: it generally encompasses the territory of the underlying ZUS or ZRU but often includes additional neighboring territories. Figure 1 shows the extent of the ZRU and the ZFU of the city of Stains in a suburban area, $10 \mathrm{~km}$ to the North from Paris. The frontier of the the ZRU is in dotted line, while the frontier of the ZFU is in plain line. In addition to the territory of the ZRU, the ZFU includes some more land, intended to be used by incoming firms. In some cases, the ZFU even combines several ZRUs from the same conurbation. Indeed, the 41 second-wave ZFUs

\footnotetext{
${ }^{8}$ The tax potential is defined as the product of local taxes for the municipality if the average national rate was applied to the municipality for each of the local rates, given the tax basis of the municipality. This variable characterizes the potential fiscal wealth of the municipality.
} 
were created on 51 initial ZRUs.

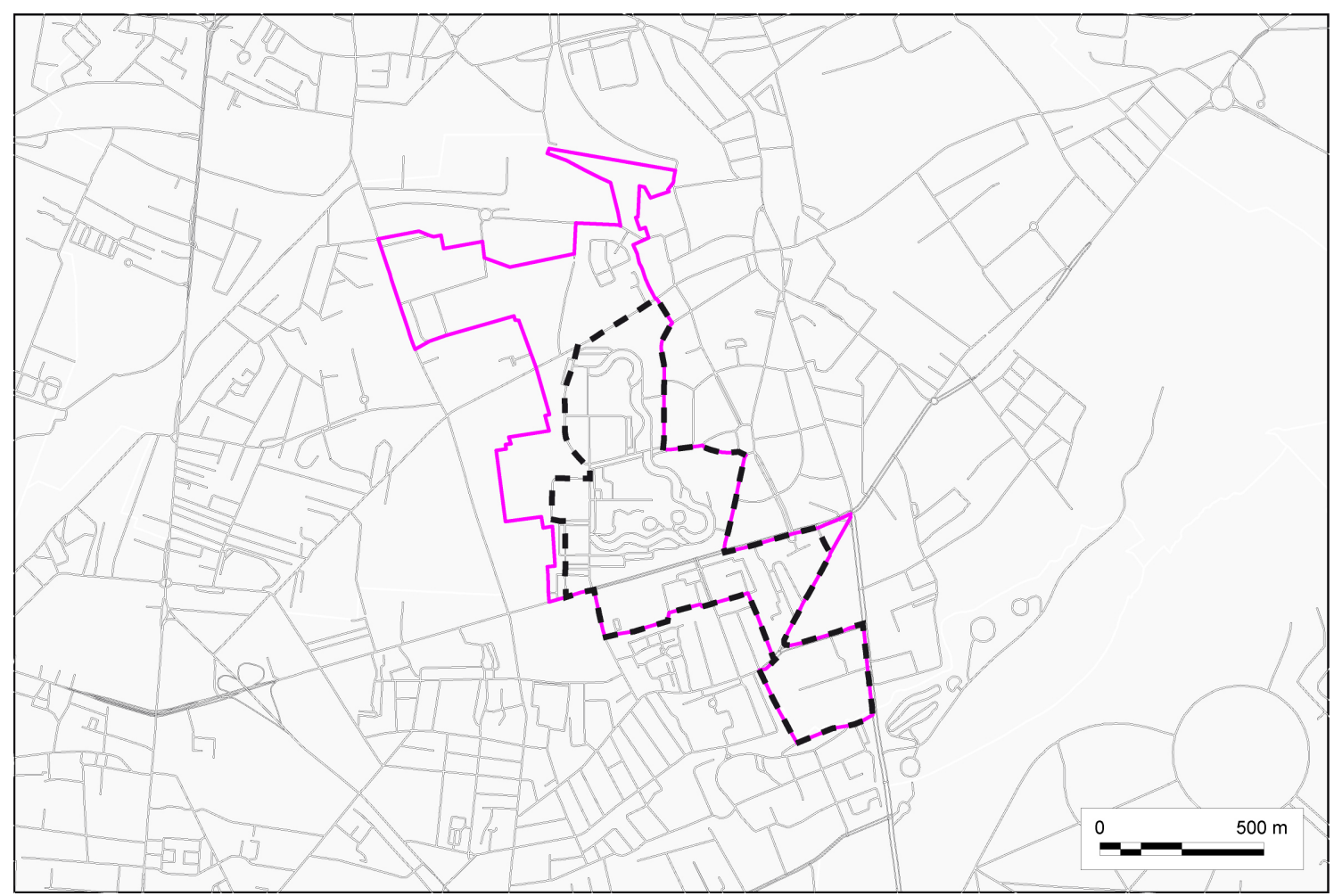

Figure 1: The ZRU (dotted line) and the ZFU in Stains, in the Northern banlieue of Paris

For the assignment process of the second wave, the index was calculated based on the 1999 population census (INSEE) and fiscal sources (General Tax Office and Ministry of Finance) which enable the determination of the tax potential for the latest available year. However, anecdotal evidence from conversations with officials of the Ministry of Urban Affairs suggest that, while policy makers had really chosen more deprived areas for the first pick in 1997, the main criteria to be included in the second wave were clearly: (ii) the metropoli$\tan$ area in which the ZRU is located and (ii) its size. First, the objective of the decision makers was to achieve a more even repartition of ZFUs at a national scale. While many major metropolitan areas (Bordeaux, Montpellier, Toulon, Nice...) had been allocated a ZFU in 1997, some important ones had not (Toulouse, Clermont-Ferrand, Nantes, Grenoble...). Figure 2 shows how relevant this assertion is all over the national territory. This point is crucial for identification as it shows that, in 2004, the allocation of the program among the ZRU can be explained by factors which are not correlated with local conditions. We provide more evidence of this below, in the section dedicated to the estimation of the propensity score. 


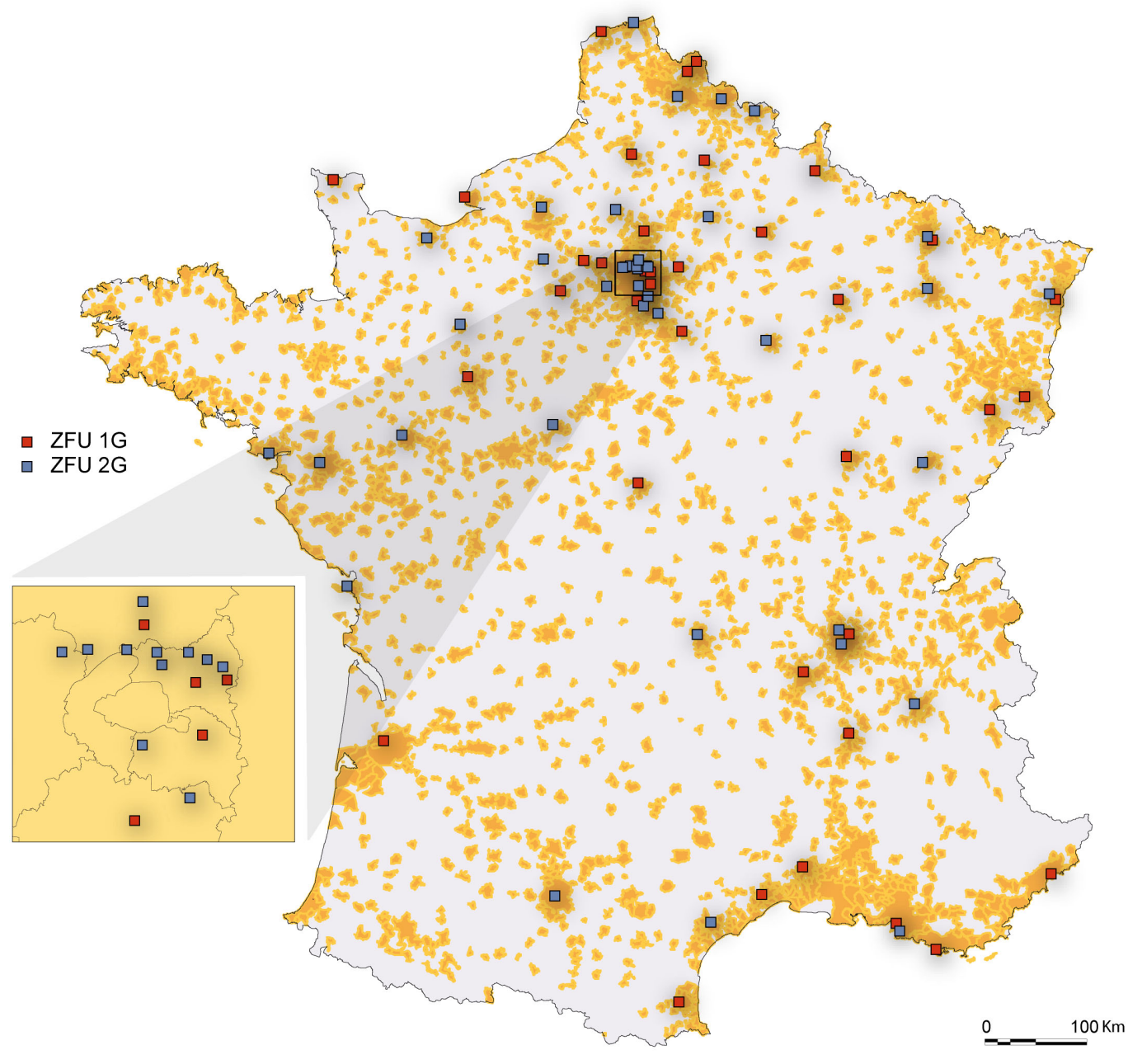

Figure 2: Locations of ZFU created in 1997 (ZFU 1G) and 2004 (ZFU 2G) in French metropolitan territory 
The second point is that size seems to matter more than other local determinants: large ZRUs that had not been picked in the first wave had to be included in the second. A closer look to the distribution of the variables composing the composite index (plus total population and the share of foreigners in the population), in the ZFUs created in 1997, in the ZFUs created in 2004 and the ZRUs that failed to be upgraded into ZFUs in 2004 show indeed that this second wave does not really correspond to the most deprived areas (Figure 3). For instance, the second wave of ZFUs has on average a smaller share of dropouts than the other ZRUs (the average rate over these areas is $29 \%$ against $33 \%$ ) as well as a smaller unemployment rate (the averages are respectively $28 \%$ and 30\%). The ZFUs of 2004 look even better off than both other groups in terms of financial capacity of municipalities. If the share of foreigners is higher in the first wave of ZFUs than in others areas, it is distributed in a similar way in ZFUs of 2004 and ZRUs. From these descriptive statistics, it may be hypothesized that, among the variables included in the official criterion, the one that really seems to make a difference between ZFUs of 2004 and other areas is the total population. This hypothesis is tested below, with the estimation of the propensity score.

Finally, in 2006, 15 new ZFUs were created among remaining ZRUs. As we focus our analysis on the second wave, we remove from the sample all the ZRUs not assigned in 2004 but assigned in 2006 . 

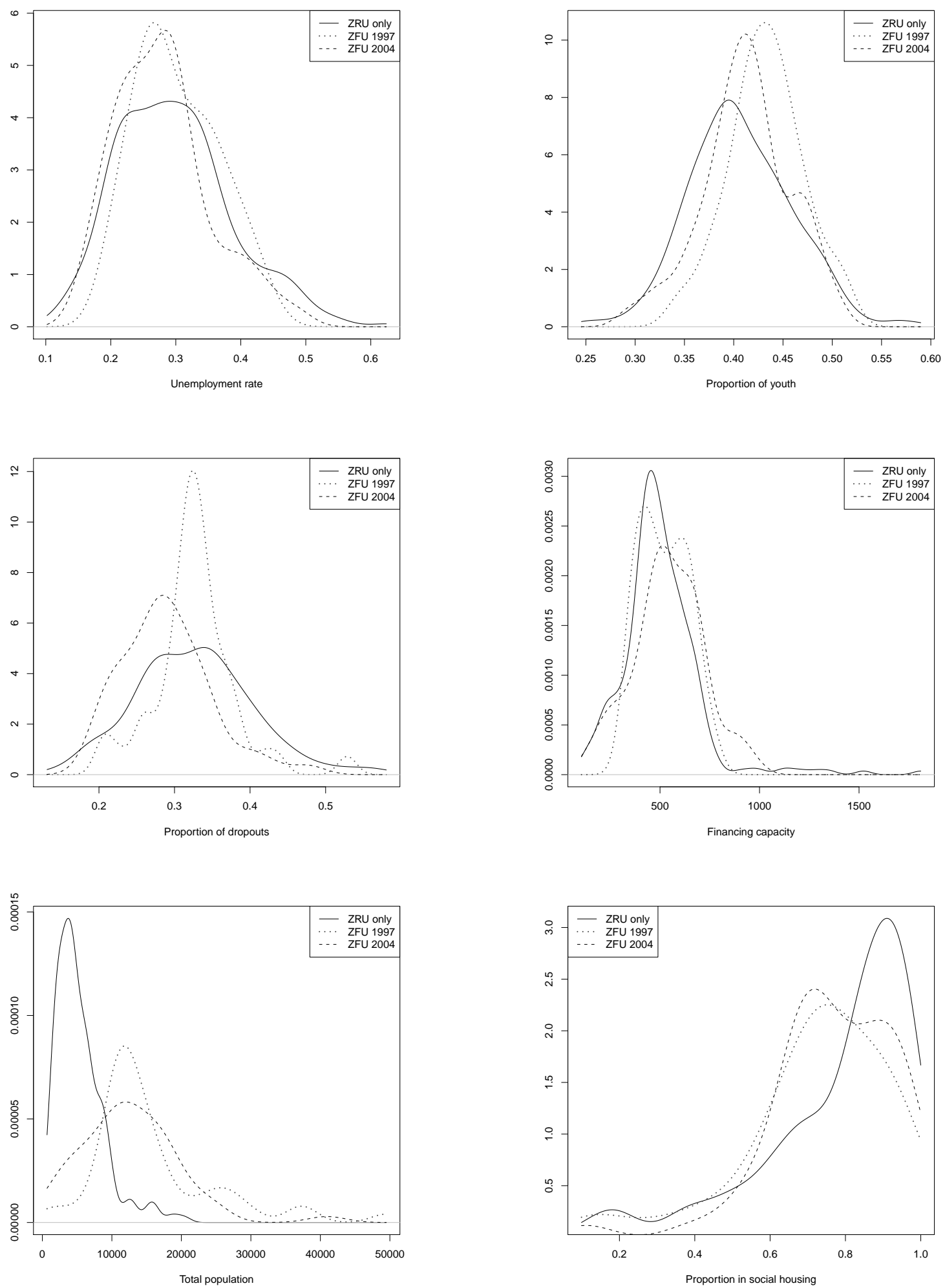

Figure 3: Estimated densities of unemployment rate, proportion of youth, proportion of dropouts, municipal financing capacity, total population, proportion of foreigners in the first generation of ZFU ('ZFU1G'), the second generation of ZFU ('ZFU2G') and ZRU that did not become ZFU ('ZRU') 


\section{Data}

\subsection{Data description}

The data we use come from several sources. The SIRENE directory (INSEE) contains exhaustive information on businesses in manufacturing, trade and services industries, in particular their location. The stock of businesses is reported yearly.New businesses are also reported, as well as their creation date and the business origin (whether a creation or a relocation). The bankruptcy file (INSEE) contains the records of all bankruptcy proceedings brought before a trade tribunal before this date. The DADS (annual declarations of social security data) dataset (INSEE) contains exhaustive information on employment and salaries in these businesses. The fiscal records, called BRN and RSI, are provided by the tax administration. These files provide accounting information (balance sheet and income statement) as well as the amount of taxes paid by every businesses. These data are available and matched over the period 2002-2007, that is from two years before the introduction in the ZFU policy.

We also use the 1999 Census (INSEE) to extract variables which characterize the sociodemographic situation of the areas under study. In particular, some of these characteristics are the criteria that were considered by decision-makers during the selection process.

Using these data, we estimate the impact of the ZFU program on economic activities measured by the stock of firms located in these areas, on firm demography (creations and failures), and on paid employment. We can also check whether this evolution is due to the new firms or to firms already present before the creation of the ZFU. Because we have access to establishment-level panel data, we can isolate businesses with at least one employee which are eligible to tax exemptions (less than fifty employees, turnover under $€ 10$ million, not held by higher corporate), located in ZRUs in 2002 . We follow the outcomes of these establishments all over the period, according to whether the ZRU in which they are located was granted ZFU in 2004 or not. As it is unlikely that these businesses anticipated the tax cuts two years before the ZFU assignment, we can rule out possible selection issues that could occur with firms located after. We can therefore measure whether tax exemptions can foster economic development of existing small firms. As micro-businesses are often said to be confronted with financial difficulties jeopardizing their survival, tax exemptions can improve their financial situation. Beyond the evolution of their employment, we will thus focus in several indicators of the economic and accounting situation: sales, current taxable income, debt, cash flow as well as investment. 


\subsection{Summary statistics}

Table 1 presents the basic statistics for considered areas in 2002, before the creation of the second wave of the ZFUs. We compare areas that are included, or not, in the ZFU program in 2004. As stated above, the 51 areas chosen to become ZFU are on average much bigger than the 284 other areas in terms of available lands and of inhabitants. Because of this size effect, more firms are initially located in these areas (187 in average compared to 84 in others areas). A large part of these are not eligible to tax exemptions granted by the program, however (meaning they have more than 50 employees or/and a turnover above $€ 10$ million). Finally, on average 37 new firms located in future ZFUs in 2002, while 15 firms did in the other areas.Most of this difference is due to scale effect : when reported to initial stock, the rates of implementations of new firms are quite similar across areas. In both groups, new businesses mainly corresponds to real creations ( $15 \%$ only corresponds to relocations).

The characteristics of eligible businesses in both groups are quite comparable across areadin 2002 (Table 2). On average, these firms are far below the threshold of 50 employees: whatever the zoning, the average labor force was around 5 employees in 2002. Their accounting situations look quite similar too.

One potential issue about our identification strategy is that we compare ZFU vs ZRU and not ZFU vs nothing else. As firms also benefit from tax incentives to set up in ZRUs, which are our control group, we run the risk of a downward bias for the estimation of the causal impact of the ZFU program. The main reason why one should not overstate this issue is provided by Figure 4. This figure displays the evolution over time of the average yearly amounts of tax exemptions for an eligible firm which was already present in the ZRU in 2002, depending on the treatment status. First, we can see that the situation in the treated and control groups are almost identical before 2004. Second, we can observe a downward trend for non-treated ZRUs, corresponding to a fade-out of the tax rebate scheme in this area. In 2003, eligible firms in ZRU reported on average a rebate of 1000 euros: 10 times less than in ZFU in 2004 and 20 times less than in ZFU in 2005 and 2006. Therefore, we certainly can consider the ZRU tax exemptions as negligible with respect to the ZFU program.

Figures 5 to 6 show the evolution over the period of the average amount of business tax and social security contributions payed by firms located in ZRUs in 2002, depending on the treatment status. For both types of tax, the curves have similar pattern in 2002 and 2003 but then diverge in the following years. Declared business tax patterns are especially 
Table 1: Economic situation in the areas in 2002

\begin{tabular}{lcc} 
& $\begin{array}{c}\text { ZRUs not turning } \\
\text { ZFU after 2004 }\end{array}$ & $\begin{array}{c}\text { ZRUs turning } \\
\text { into ZFU in 2004 }\end{array}$ \\
\hline Total population & 5,433 & 12,644 \\
Area $\left(\mathrm{km}^{2}\right)$ & 77.2 & 135.4 \\
Number of firms & 84 & 187 \\
Number of workers & 389 & 685 \\
Firm demography (per yr.) & & \\
New firms & 15.27 & 37.45 \\
Creations & 12.68 & 31.47 \\
Transfers & 2.59 & 5.98 \\
New firms (/ Stock in 2001) & 0.19 & 0.21 \\
Creations (/ Stock in 2001) & 0.16 & 0.18 \\
Transfers (/ Stock in 2001) & 0.03 & 0.03 \\
Industries & & \\
Share of manuf. & 0.11 & 0.12 \\
Share of retail & 0.36 & 0.32 \\
Share of construction & 0.24 & 0.25 \\
Share of services to hh. & 0.15 & 0.15 \\
Share of B. to B. & 0.08 & 0.10 \\
Share of transportation & 0.04 & 0.04 \\
\hline Number of ZRUs & 284 & 51 \\
\hline
\end{tabular}


Table 2: Descriptive statistics for eligible firms in 2002

\begin{tabular}{lcc}
\hline & $\begin{array}{c}\text { area no turning } \\
\text { into EZ after 2004 }\end{array}$ & $\begin{array}{c}\text { area turning } \\
\text { into EZ in 2002 }\end{array}$ \\
\hline Number of workers & 4.96 & 5.10 \\
Hourly wage (euro) & 10.54 & 10.64 \\
Sales (x 1,000 euro) & 250.22 & 232.00 \\
Income (x 1,000 euro) & 35.50 & 33.03 \\
Cash flow (x 1,000 euro) & 26.61 & 25.87 \\
Investment (x 1,000 euro) & 12.55 & 11.58 \\
Debt (x 1,000 euro) & 93.67 & 93.38 \\
\hline Average number of & & 38 \\
eligible firms per area & 21 & \\
\hline
\end{tabular}

spectacular, growing all over the period in the ZRUs while remaining at low levels in ZFUs. This is consistent with the fact that the sample considered in these figures are the establishments that already existed in 2002: the number of firms in the sample decreases over time and their average size (in terms of employment or sales) increases. In 2007, the companies of our sample located in second-generation ZFUs claimed they paid $€ 800$ in business tax, i.e. five times less than similar companies located in ZRUs which are not ZFUs. A comparable evolution is observed for social security contributions: the ZFU program has resulted in a stabilization although the amounts tend to increase after $2004 .^{9}$ The amount of social security contributions declared by the companies in second-generation ZFUs is, as of 1 January $2007, € 4,300$ on average, i.e. the same figure as at the time of ZFU classification (Figure 6). For the companies located in ZRUs not classified as ZFUs, this amount is on average $€ 5,000$ in 2007. As of 1 January 2002, these companies declared average amounts of $€ 3,500$ whether or not they were located in future ZFUs. Overall we may conclude from these figures that the ZFU program strongly contributed, all along the period, to alleviate firms' tax burden, even compared with neighborhoods in which tax rebates were also proposed.

\footnotetext{
${ }^{9}$ As the exemptions of social security contributions are conditional on hiring local workers, this result might signal that, whether they would not or could not, a substantial share of firms in treated areas did not fulfill this local hiring condition.
} 


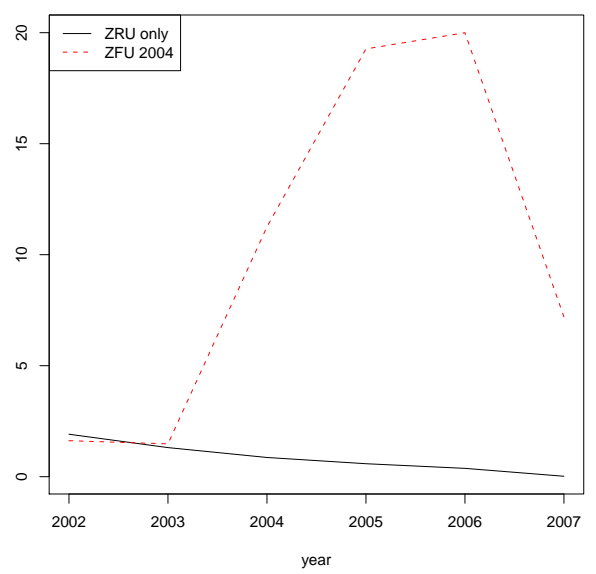

Figure 4: Declared exemption amount per area (thousand Euros)

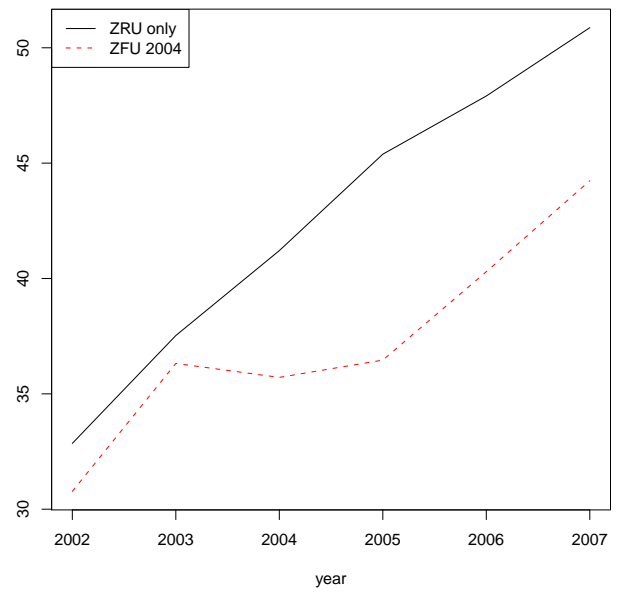

Figure 6: Declared amount of social security contributions (thousand Euros)

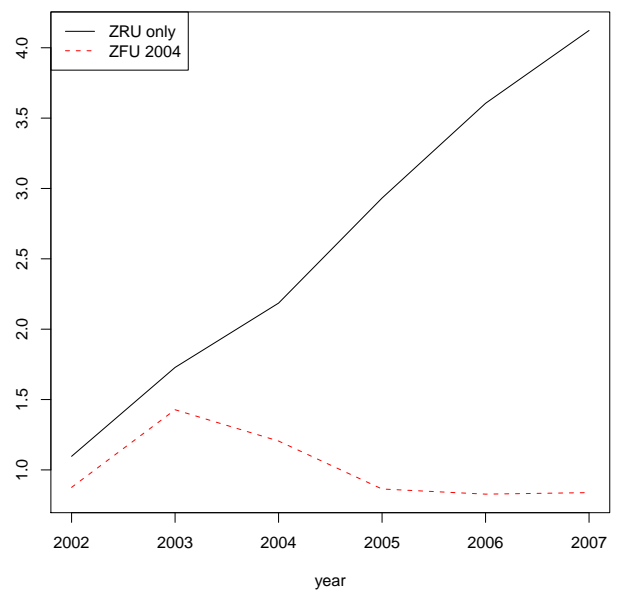

Figure 5: Declared business tax amount (thousand Euros) 


\section{Methodology}

Ideally, the effect we want to measure would be obtained by calculating the difference in the dependent variable between the units which are actually treated and on the same units but in a scenario in which they would have not been treated. While we can directly observe the former, the latter is unobservable as the units in question have been treated. The ZFU program is granted to areas that experience economic and social issues. Therefore, direct comparison of all treated and all non-treated units could lead to spurious results, probably understating the true impact of the program.

As detailed below, we choose an empirical strategy that consists of choosing a control group of areas as close as possible to ZFUs. The pool of ZRUs which were not affected to the program is an obvious choice, given the assignment process of the second wave. Our identification assumption states that, conditional on characteristics observed before assignment, the affectation of a ZRU to the ZFU program is not related to the potential outcome.

Formally speaking, we can consider that any ZRU $i$ has virtually two potential outcomes, at time $t$ : one referred to as $Y_{i t}^{1}$, if it is located in a ZFU, and the other, referred to as $Y_{i t}^{0}$, if it is not. The impact of the ZFU program at time $t$ on this area is equal to $Y_{i t}^{1}-Y_{i t}^{0}$, with $t$ posterior to the date of $\mathrm{ZFU}$ affectation. It will never be possible to estimate this impact as we can never simultaneously observe both potential outcomes for the same unit at the same time. In order to obtain an evaluation of the counterfactual outcome, we use a conditional difference-in-differences strategy. The identifying assumption states that conditionally to observable characteristics, all remaining differences (that could impact outcome) between the units are not associated with the treatment. This is supported by the fact that we could use time-differentiated outcomes, and thus eliminate potential systematic differences between the areas (see Heckman et al. 1998).

$$
\Delta Y_{i t}^{0} \perp T_{i} \mid X_{i}
$$

To overcome the problem of dimensionality arising when using too many observables, we perform a propensity score matching. As shown by Rosenbaum \& Rubin (1983), if the conditional independence assumption holds for observables $X$, it also holds for the propensity score, i.e. the probability of being treated conditional on these observables. In other words, hypothesis (1) implies

$$
\Delta Y_{i t}^{0} \perp T_{i} \mid p\left(T_{i}=1 \mid X_{i}\right) .
$$

In practice, the estimation is a two-stage process: the estimation of the propensity score 
followed by the matching itself. We estimate this propensity score using a logit model.

Table 3: Probability for a area in 2003 to be part of a ZFU in 2004

\begin{tabular}{|c|c|}
\hline Variables & $\begin{array}{l}\text { Probability of belonging } \\
\text { to a ZFU in } 2004\end{array}$ \\
\hline Intercept & $\begin{array}{l}441.18 \\
(300.66)\end{array}$ \\
\hline Distance to closest ZRU $<2 \mathrm{~km}$ & $\begin{array}{c}1.25^{* *} \\
(0.51)\end{array}$ \\
\hline Distance to closest ZRU $<5 \mathrm{~km}$ & $\begin{array}{c}1.22^{* *} \\
(0.59)\end{array}$ \\
\hline Distance to closest ZFU1997 $>30 \mathrm{~km}$ & $\underset{(0.63)}{2.27^{* * *}}$ \\
\hline Log total population & $\begin{array}{l}-144.78 \\
(105.43)\end{array}$ \\
\hline Log total population ${ }^{2}$ & $\begin{array}{l}15.58 \\
(12.26)\end{array}$ \\
\hline Log total population ${ }^{3}$ & $\begin{array}{l}-0.54 \\
(0.47)\end{array}$ \\
\hline Fiscal potential & $\begin{array}{c}-1.21^{*} \\
(0.71)\end{array}$ \\
\hline Log employment & $\begin{array}{l}0.29 \\
(0.30)\end{array}$ \\
\hline Proportion of social housing & $\begin{array}{l}0.79 \\
(0.90)\end{array}$ \\
\hline Proportion of youth & $\begin{array}{l}3.85^{*} \\
(2.10)\end{array}$ \\
\hline Proportion of dropouts & $\begin{array}{c}0.48 \\
(1.40)\end{array}$ \\
\hline Unemployment rate & $\begin{array}{c}-0.80 \\
(1.18)\end{array}$ \\
\hline Log number of establishments & $\begin{array}{l}-0.37 \\
(0.93)\end{array}$ \\
\hline Log number of small eligible ones & $\begin{array}{c}-0.22 \\
(0.53)\end{array}$ \\
\hline Log number of large eligible ones & $\begin{array}{c}-0.08 \\
(0.47)\end{array}$ \\
\hline Number of ZFU 2004 observations & 50 \\
\hline Number of non-ZFU 2004 observations & 250 \\
\hline
\end{tabular}

Note: Probit estimation. The standard deviation of the estimator is in brackets. Three (respectively two, one) stars indicate a $1 \%$ significance (respectively $5 \%, 10 \%$ ).

For conditioning variables, we use the variables that enter in the composite index used by decision makers to decide which area would be assigned to the ZFU program (see Section 2 ), as well as variables reflecting the local economic situation at the start of the period. As the total population is likely to play in a non-linear way, we introduce it in the propensity equation as a third-degree polynomial. We also introduce two variables related to the relative distance of the zones. The equation is estimated using a logit. 
As expected by our descriptive analysis, areas that turned into ZFUs in 2004 tend to concentrate slightly more social issues than ZRU, yet most of the coefficients are insignificant (see Table 3). Only the fiscal potential and the share of youth are significantly associated with assignment probability. In spite of what appeared in descriptive analysis, population seems to play no significant role, once other covariates are accounted for. In the contrary, coefficients relating to distance variables are strongly significant. We argued in section 2 that, for a ZRU in 2003, the distance to a first wave ZFU and to another ZRU should affect positively the probability to be assigned to treatment: the former because it leads to a more even repartition of ZFUs at the national scale, and the latter because ZRUs could be merged in order to constitute a zone achieving the required size.

Overall, the results of the propensity score estimation are compatible with our view, built on anecdotal evidence and summary statistics, according to which selection bias should be of second-order. First, because it turns out that the most important predictor for the assignment to the treatment is the distance to ananother ZRU or to first-wave ZFU. Second, because social covariates, even those who should have been taken into account by decision-makers, do not differ that much between treated and control groups. Even economic variables, like the stock of firms, are bluntly insignificant.

In the second stage, each treated unit is matched with untreated units with a similar propensity score. We used a kernel matching method: untreated observations are weighted according to their distance from the treated observation, the weightings being determined by a (Gaussian) kernel. At the end of this matching process, the estimated effect of the treatment is obtained for each treated unit. The average effect of the treatment is then calculated by considering the average of individual differences.

As demonstrated in particular by Bertrand et al. (2004), the inference is biased by both group effects (the businesses in the same areas can experience joint shocks) and serial correlation in residuals. Our estimation is not affected by this issue as we we choose to work at the ZRU level. Full bootstrap on ZRUs is used for inference. 


\section{$5 \quad$ Results}

\subsection{The impact of the program on the treated areas}

In this section, we report the results of our propensity-score matching estimations, on a large set of outcomes (firm demography, employment, economic situation of preexisting firms) for each year between 2003 and 2007. ${ }^{10}$ Let us stress that the program started, for the second wave of ZFU, in 2004. Year 2003 thus constitutes a "falsification test" in the sense of Manning \& Pischke (2006): if the control group is a valid counterfactual for the treatment group then control and treated areas should not differ before the program is enforced. This falsification test can be considered as a test of our identification assumption. For all the outcomes considered in this study, there is no significant differences between our treatment and (matched) control groups before the introduction of the tax exemptions (Tables 4 to 6 ).

The overall impact of the ZFU program on the economic activity is positive from the starting date of the treatment until 2007 (Table 4). In particular, the growth rate of the stock of companies is 5 pp. higher in the treated ZRUs than in the control group in 2004 and 2005. In the following years, the effect remains positive but is no longer significant. Such a positive effect could be explained in two ways. At the intensive margin, the ZFU program could have helped pre-existing firms not to exit. At the extensive margin, the program could have fostered firms' births or relocations to the treated areas.

When we focus on companies that were already present in the area in 2002, there is a positive difference in favor of the treatment group,${ }^{11}$ especially for the companies with less than 3 employees, but this effect is neither significant nor persistent over time. Moreover, the number of failures is not statistically different across groups. Both results suggest that the surviving rates of pre-existing companies are not statistically affected by the ZFU program.

On the contrary, the program seems to have a large effect in luring new business into the areas benefiting from tax subsidies. The inflow rate, measured as the ratio of new firms in the current year over the stock on January 1st, is increased by 7 pp. in 2004, 4 pp. in 2005, 6 pp. in 2006 by the treatment. The effect is still positive but insignificant in 2007. These new establishments could be relocations of existing ones or pure creations: we estimate the treatment effect separately for both outcomes and reach two conclusions.

\footnotetext{
${ }^{10}$ Descriptive statistics, figures production and econometric treatments have been carried out using the software R (R Development Core Team 2010).

${ }^{11}$ We chose this threshold, as the median establishment present in 2002 in our sample has 3 employees.
} 
First, the schedule of the treatment effects on births and relocations are different. The impact on pure creations is significant in first two years, while the impact on relocation is stronger in 2006 and 2007: creations went first, and relocations went only in a second stage. Second, compared to the average creation and relocation rates (see Table 1), the program has a much more important relative impact on relocations. In 2002, the creation rate was on average .16 while the relocation rate was .03 . Thus, a 3 pp. increase on the creation rate represents a $19 \%$ relative increase, while a 3 pp. increase on the relocation rate means there are twice as many relocations as what is observed on average. In relative terms, the impact is much higher on relocations than on creations.

Table 4: Impact of the transition to ZFU on stock of companies and firms demography

\begin{tabular}{|c|c|c|c|c|c|}
\hline \multirow[t]{2}{*}{ Variables } & \multicolumn{5}{|c|}{ Years } \\
\hline & 2003 & 2004 & 2005 & 2006 & 2007 \\
\hline \multicolumn{6}{|l|}{ Stock (log) } \\
\hline Number of establishments & $\begin{array}{l}0.02 \\
(0.04)\end{array}$ & $\underset{(0.02)}{0.05^{* * *}}$ & $\begin{array}{c}0.05^{* * *} \\
(0.02)\end{array}$ & $\begin{array}{l}0.04 \\
(0.02)\end{array}$ & $\begin{array}{l}0.03 \\
(0.03)\end{array}$ \\
\hline \multicolumn{6}{|c|}{ Amongst companies eligible already present in 2002 } \\
\hline & $\begin{array}{c}-0.02 \\
(0.03)\end{array}$ & $\begin{array}{l}0.03 \\
(0.05)\end{array}$ & $\begin{array}{l}0.01 \\
(0.06)\end{array}$ & $\begin{array}{c}-0.02 \\
(0.04)\end{array}$ & $\begin{array}{c}-0.02 \\
(0.06)\end{array}$ \\
\hline \multicolumn{6}{|c|}{...with less than 3 employees in 2002} \\
\hline & $\begin{array}{c}-0.06 \\
(0.04)\end{array}$ & $\begin{array}{l}0.06 \\
(0.08)\end{array}$ & $\begin{array}{l}0.05 \\
(0.10)\end{array}$ & $\begin{array}{l}0.02 \\
(0.06)\end{array}$ & $\begin{array}{r}-0.06 \\
(0.09)\end{array}$ \\
\hline \multicolumn{6}{|c|}{...with more than 4 employees in 2002} \\
\hline & $\begin{array}{l}0.02 \\
(0.05)\end{array}$ & $\begin{array}{l}0.01 \\
(0.05)\end{array}$ & $\begin{array}{c}-0.04 \\
(0.06)\end{array}$ & $\begin{array}{c}-0.02 \\
(0.06)\end{array}$ & $\begin{array}{l}0.03 \\
(0.07)\end{array}$ \\
\hline \multicolumn{6}{|c|}{ Amongst companies eligible already present in 2002} \\
\hline Failures (for 1,000 companies) & $\begin{array}{l}1.40 \\
(1.67)\end{array}$ & $\begin{array}{l}0.04 \\
(2.30)\end{array}$ & $\begin{array}{l}1.24 \\
(1.64)\end{array}$ & $\begin{array}{c}-1.93 \\
(2.07)\end{array}$ & $\begin{array}{l}0.08 \\
(1.65)\end{array}$ \\
\hline \multicolumn{6}{|c|}{ Flow (relatively to the previous stock) } \\
\hline New establishments & $\begin{array}{l}0.00 \\
(0.03)\end{array}$ & $\begin{array}{c}0.07^{* * *} \\
(0.02)\end{array}$ & $\begin{array}{l}0.04^{*} \\
(0.02)\end{array}$ & $\begin{array}{c}0.06^{* *} \\
(0.03)\end{array}$ & $\begin{array}{l}0.04 \\
(0.02)\end{array}$ \\
\hline Creations & $\begin{array}{l}0.01 \\
(0.02)\end{array}$ & $\begin{array}{c}0.04^{* * *} \\
(0.01)\end{array}$ & $\begin{array}{c}0.03^{* *} \\
(0.02)\end{array}$ & $\begin{array}{l}0.03 \\
(0.02)\end{array}$ & $\begin{array}{l}0.00 \\
(0.02)\end{array}$ \\
\hline Transfers & $\frac{-0.01}{(0.01)}$ & $\begin{array}{c}0.02^{* * *} \\
(0.01)\end{array}$ & $\begin{array}{l}0.01 \\
(0.01)\end{array}$ & $\begin{array}{c}0.03^{* * *} \\
(0.01)\end{array}$ & $\begin{array}{c}0.03^{* *} \\
(0.01)\end{array}$ \\
\hline
\end{tabular}

Note: The standard deviation of the estimator is in brackets, estimated by block bootstraps in areas. Three (respectively two, one) stars indicate a $1 \%$ significance (respectively $5 \%, 10 \%$ ). All results featured herewith correspond with a Gaussian kernel matching method.

Table 5 presents the impact of the ZFU program on employment outcomes. Two outcomes 
are considered: the annual growth rate of the number of employees in a given establishment on December 31st, and the annual growth of the number of worked hours. Interestingly, the impact of the treatment is similar on both measures, which means that the program has no impact on the number of hours worked per worker. Overall, employment is boosted by the treatment, yet the effect is significant only for years 2005 and 2007 . The growth rate of employment is increased by 7 to $8 \mathrm{pp}$ in 2005 as a result of the ZFU program. In 2007, the effect is even larger, with an impact of $20 \mathrm{pp}$.

Is this positive effect due to new or to pre-existing firms? When we focus on establishments that were already present in 2002, we find much more modest effects. Out of 24 coefficients (2 outcomes, from 2004 to 2007, for all existing firms as well as two subgroups), only two are significant and positive, which is not enough to assert that the program has indeed an effect on the employment growth rate in the pre-existing eligible firms.

Table 5: Impact of the transition to ZFU on employment (log)

\begin{tabular}{|c|c|c|c|c|c|}
\hline \multirow[t]{2}{*}{ Variables } & \multicolumn{5}{|c|}{ Years } \\
\hline & 2003 & 2004 & 2005 & 2006 & 2007 \\
\hline \multicolumn{6}{|l|}{ All companies } \\
\hline Employment & $\begin{array}{l}0.03 \\
(0.07)\end{array}$ & $\begin{array}{l}0.04 \\
(0.05)\end{array}$ & $\begin{array}{l}0.07^{*} \\
(0.04)\end{array}$ & $\begin{array}{l}0.05 \\
(0.08)\end{array}$ & $\begin{array}{c}0.21^{* * *} \\
(0.07)\end{array}$ \\
\hline Hours & $\begin{array}{l}0.02 \\
(0.06)\end{array}$ & $\begin{array}{l}0.05 \\
(0.05)\end{array}$ & $\begin{array}{c}0.08^{*} \\
(0.04)\end{array}$ & $\begin{array}{l}0.05 \\
(0.09)\end{array}$ & $\begin{array}{c}0.22^{* * *} \\
(0.07)\end{array}$ \\
\hline \multicolumn{6}{|c|}{ Amongst companies eligible already present in 2002 } \\
\hline Employment & $\begin{array}{l}0.01 \\
(0.04)\end{array}$ & $\begin{array}{l}0.02 \\
(0.07)\end{array}$ & $\begin{array}{c}-0.05 \\
(0.07)\end{array}$ & $\begin{array}{l}0.08 \\
(0.11)\end{array}$ & $\begin{array}{c}0.07^{*} \\
(0.04)\end{array}$ \\
\hline Hours & $\begin{array}{l}0.00 \\
(0.04)\end{array}$ & $\begin{array}{l}0.03 \\
(0.07)\end{array}$ & $\begin{array}{c}-0.07 \\
(0.07)\end{array}$ & $\begin{array}{l}0.07 \\
(0.09)\end{array}$ & $\begin{array}{l}0.04 \\
(0.04)\end{array}$ \\
\hline \multicolumn{6}{|c|}{...with less than 3 employees in 2002} \\
\hline Employment & $\begin{array}{l}0.04 \\
(0.07)\end{array}$ & $\begin{array}{c}-0.05 \\
(0.08)\end{array}$ & $\begin{array}{l}0.03 \\
(0.11)\end{array}$ & $\begin{array}{l}0.10 \\
(0.09)\end{array}$ & $\begin{array}{l}0.11 \\
(0.08)\end{array}$ \\
\hline Hours & $\begin{array}{l}0.05 \\
(0.07)\end{array}$ & $\begin{array}{c}-0.06 \\
(0.07)\end{array}$ & $\begin{array}{l}0.02 \\
(0.10)\end{array}$ & $\begin{array}{l}0.12^{*} \\
(0.07)\end{array}$ & $\begin{array}{l}0.02 \\
(0.07)\end{array}$ \\
\hline \multicolumn{6}{|c|}{...with more than 4 employees in 2002 } \\
\hline Employment & $\begin{array}{c}-0.03 \\
(0.05)\end{array}$ & $\begin{array}{l}0.05 \\
(0.07)\end{array}$ & $\begin{array}{c}-0.05 \\
(0.06)\end{array}$ & $\begin{array}{l}0.07 \\
(0.12)\end{array}$ & $\begin{array}{l}0.05 \\
(0.05)\end{array}$ \\
\hline Hours & $\begin{array}{c}-0.04 \\
(0.05)\end{array}$ & $\begin{array}{l}0.07 \\
(0.06)\end{array}$ & $\begin{array}{c}-0.08 \\
(0.07)\end{array}$ & $\begin{array}{l}0.05 \\
(0.10)\end{array}$ & $\begin{array}{l}0.03 \\
(0.05)\end{array}$ \\
\hline
\end{tabular}

Note: The standard deviation of the estimator is in brackets, estimated by block bootstraps in areas. Three (respectively two, one) stars indicate a $1 \%$ significance (respectively $5 \%, 10 \%$ ). All results featured herewith correspond with a Gaussian kernel matching method. 
Table 6 reports the impact of the program on accounting variables of establishments already set up in 2002. For income, sales and hourly wages, the impact on the growth rate is reported while, for cash flow, debt and investment, the impact is computed on the annual difference in the ratio of the outcomes divided by the volume of sales. Once more, as only one coefficient appears significant, we cannot reject the fact that ZFU had no impact on the economic situation of pre-existing firms.

Table 6: Impact of the transition to ZFU on wages and accounting indicators, for eligible companies existing in 2002

\begin{tabular}{lccccc}
\hline \multirow{2}{*}{ Variables } & \multicolumn{5}{c}{ Years } \\
\cline { 2 - 6 } & 2003 & 2004 & 2005 & 2006 & 2007 \\
\hline \multirow{2}{*}{ All eligible companies present in 2002 } & & & \\
Income (log) & 0.00 & $-0.04^{* * *}$ & -0.00 & -0.02 & 0.02 \\
& $(0.01)$ & $(0.01)$ & $(0.01)$ & $(0.02)$ & $(0.02)$ \\
Sales (log) & -0.00 & 0.01 & -0.08 & 0.07 & 0.04 \\
& $(0.05)$ & $(0.07)$ & $(0.06)$ & $(0.07)$ & $(0.07)$ \\
Hourly wage (log) & 0.00 & -0.00 & 0.01 & 0.02 & 0.01 \\
& $(0.03)$ & $(0.01)$ & $(0.02)$ & $(0.02)$ & $(0.02)$ \\
Cash flow / Sales & -0.01 & 0.01 & -0.00 & -0.03 & 0.02 \\
& $(0.01)$ & $(0.02)$ & $(0.01)$ & $(0.03)$ & $(0.02)$ \\
Debt/ Sales & -0.03 & -0.02 & -0.03 & -0.02 & 0.01 \\
& $(0.03)$ & $(0.03)$ & $(0.05)$ & $(0.03)$ & $(0.04)$ \\
Investment/ Sales & -0.02 & 0.02 & 0.01 & 0.00 & -0.03 \\
& $(0.03)$ & $(0.02)$ & $(0.01)$ & $(0.01)$ & $(0.03)$ \\
\hline
\end{tabular}

Note: The standard deviation of the estimator is in brackets, estimated by block bootstraps in areas.

Three (respectively two, one) stars indicate a 1\% significance (respectively 5\%, 10\%). All results featured herewith correspond with a Gaussian kernel matching method.

To sum up, the ZFU had a strong impact on the number of firms located in the treated areas. This impact is mainly driven by an increase in the new firms, both births and relocations. In relative terms though, the increase is mainly due to a surge of the number of firms relocating. The program also had an impact on total employment in the area, both measured in jobs and worked hours. However, the program does not seem to have an effect whatsoever on establishments that already existed in 2002. While these existing firms were as eligible as new ones to tax exemptions, their survival rate, their employment level, as well as their economic situation were essentially unaffected by the program. 


\subsection{Spatial externalities}

As the program appears to have been successful in attracting new firms within the boundaries of the treated ZFU, an obvious issue is whether the improvement was made at the expense of neighboring areas. The relative importance of business relocations among the new businesses raises concern about the existence of negative geographical externalities, at least in the short run, of the ZFU program. Spillovers could also have affected creations: a firm willing to create a new establishment on a given spot may change its mind if a ZFU is created nearby and may decide to locate within the ZFU instead, in order to benefit from tax exemptions. If theory would predict such negative spillover in the short run, the geographical concentration of a growing number of firms may also bring about, in a longer run, positive externalities due to agglomeration economies.

In this section, we address the issue of the existence of such externalities by measuring the impact of the program not on the treated area itself but on a neighboring ring around the treated. More precisely, we build a 300-meter-wide ring of land around all the ZFUs ${ }^{12}$ that constitute here the population of interest. Figure 7 displays what the ring looks like in the case of the ZFU of Stains.

Note that the issue here is somewhat different than in the previous sections : we do not measure the impact of local tax subsidies on targeted areas, but the impact of being near some areas benefiting from these tax subsidies. The control areas, for the sake of comparability, are similarly-built 300-meter-wide rings around the ZRUs which were not included in the ZFU program in 2004. The 300-meter width is purely conventional, and the exercise could be reproduced with rings of different widths. We chose to build rings of this size as they lead to surfaces of land which are similar to that of the interior of a typical ZFU. Once our treated and control groups are defined, we conduct a similar analysis as in the previous section, using a set of outcomes reduced to the ones on which a direct impact was observed. Note again that our question is the fact of being near a ZFU. We thus match each neighborhood of an area according to the propensity score of this area. Each ring is therefore assigned the propensity score corresponding to the interior of the ZFU or the ZRU. As before, full bootstrap is used for inference.

Same falsification test than before shows that before treatment ZFU rings are no significantly different from the rings of other areas, apart for a small positive difference on the

\footnotetext{
${ }^{12}$ The mapping technology used to build these areas is quite similar to that used in Neumark \& Kolko (2010).
} 


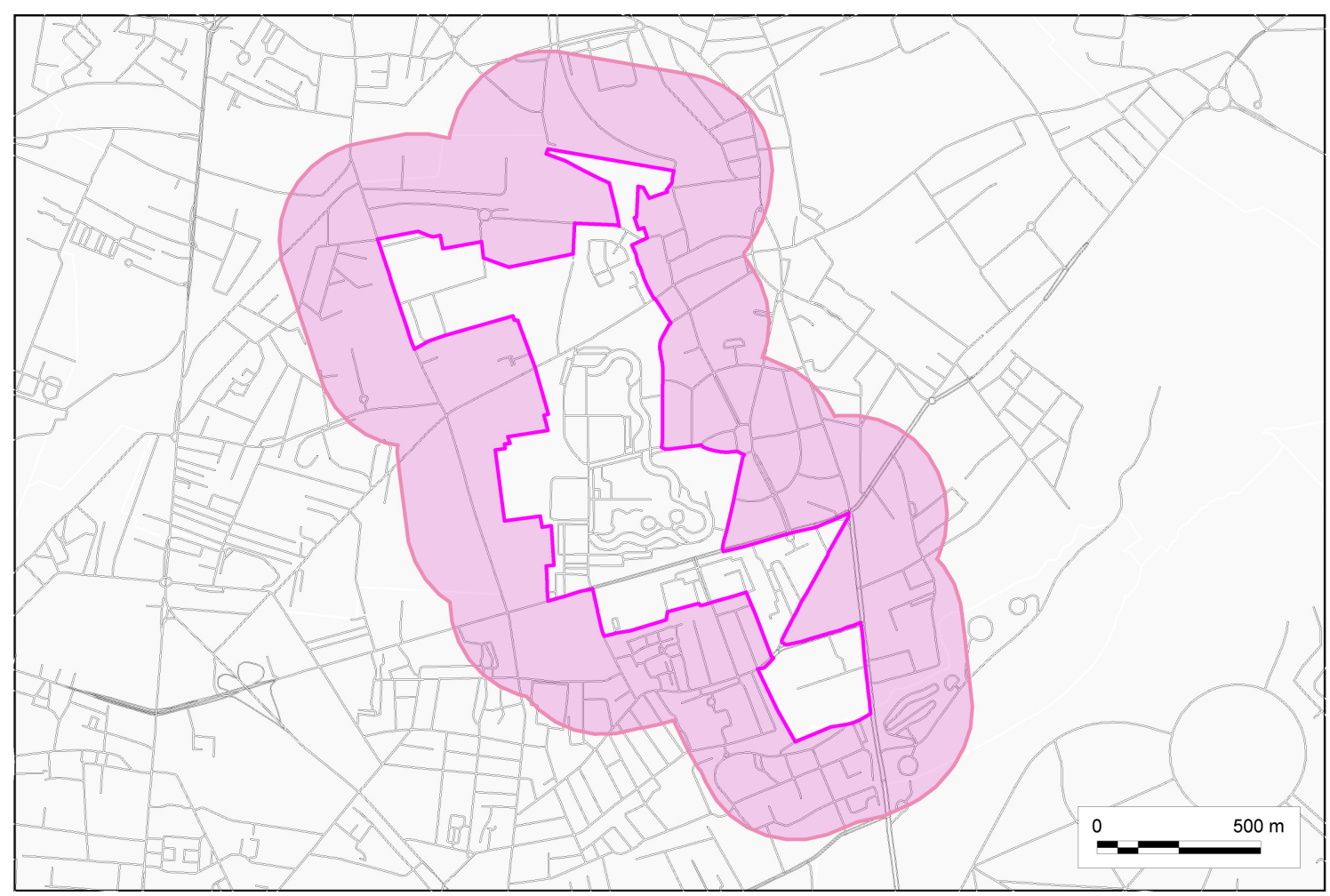

Figure 7: The ZFU and its 300-meter-wide ring in Stains, in the Northern banlieue of Paris

(time-differenced) relocation rate. This is a quite reassuring fact about the comparability between this two groups (Table 7). Summary statistics (see Table 8 in Appendix B) also show that, while there is a scale difference between rings around ZFUs and ZRUs, the former being on average twice as large as the latter, they display almost identical business location rates in 2002 .

Now, what about the impact of being a neighboring zone of the ZFU program? The program provoked significant negative spillovers on economic activity, at least during the first three years (from 2004 to 2006). We observe a significant decline of the growth rate of the number of establishments located in the rings surrounding a ZFU, with respect to the rings surrounding ZRUs. We also remark a negative impact of the inflows of new establishments. This decline, perhaps not surprisingly, follows the same pattern that the direct effect: at first, effects on the firms' births, then effects on the relocations. Conversely, in spite of negative coefficients, no significant spillover is observed on employment outcomes. Finally, we note that spillover effectson economic activity have more or less the same magnitude that direct effects. This tends to prove that most of the direct impact of the ZFU program is compensated by losses in the neighboring territories, just beyond the ZFU boundary. 
Table 7: Impact of the ZFU program on a ring around the treated area

\begin{tabular}{lccccc}
\hline \multirow{2}{*}{ Variables } & \multicolumn{3}{c}{ Years } \\
\cline { 2 - 6 } & 2003 & 2004 & 2005 & 2006 & 2007 \\
\hline \multirow{2}{*}{ Number of establishments (Log) } & -0.02 & $-0.07^{* * *}$ & $-0.05^{*}$ & -0.06 & -0.03 \\
& $(0.03)$ & $(0.02)$ & $(0.03)$ & $(0.04)$ & $(0.04)$ \\
Total employment (Log) & -0.05 & -0.04 & -0.03 & -0.11 & 0.02 \\
& $(0.13)$ & $(0.06)$ & $(0.04)$ & $(0.09)$ & $(0.09)$ \\
Total number of hours (Log) & 0.01 & $-0.09^{*}$ & -0.03 & -0.11 & -0.01 \\
& $(0.13)$ & $(0.05)$ & $(0.04)$ & $(0.11)$ & $(0.10)$ \\
\hline \multirow{2}{*}{ Flow (relatively to the previous stock) } & & & & \\
New establishments & -0.07 & -0.04 & $-0.06^{* *}$ & $-0.10^{*}$ & -0.05 \\
Creations & $(0.05)$ & $(0.03)$ & $(0.03)$ & $(0.05)$ & $(0.04)$ \\
Transfers & -0.08 & -0.03 & $-0.03^{*}$ & -0.01 & -0.01 \\
& $(0.05)$ & $(0.03)$ & $(0.02)$ & $(0.02)$ & $(0.02)$ \\
& $0.01^{*}$ & $-0.01^{*}$ & $-0.03^{* *}$ & $-0.08^{*}$ & $-0.04^{*}$ \\
\hline
\end{tabular}

Note: The standard deviation of the estimator is in brackets, estimated by block bootstraps in areas.

Three (respectively two, one) stars indicate a $1 \%$ significance (respectively $5 \%, 10 \%$ ). All results featured herewith correspond with a Gaussian kernel matching method. 


\section{Conclusion}

All in all, we observe a significant positive impact of the Zones Franches Urbaines placebased tax-exemption program on economic activities, in contrast with part of the previous studies on this kind of policy. This impact is mostly due to the fact that new companies are created or relocated in the treated areas. The impact on preexisting companies is surprisingly almost never significant, despite substantial financial transfers. Moreover, the policy also seems to have substantial negative spillovers on the neighboring areas: the presence of a ZFU depresses the location of new businesses in the immediate vicinity of the treated area.

Our results suggest that this place-based tax-exemption policies may have an impact beyond simple windfall effects. They also suggest that the policy was inefficient on part of its target, namely, the firms which were located in the treated areas before the treatment started. For these firms, we observe no effect on survival rate, employment, or economic health. This piece of evidence clearly questions the relevance of granting eligibility to preexisting firms.

If the ZFU policy has managed to bring some jobs back in distressed areas, it might not have been so successful in bring local job-seekers to employment. Using public-employmentservice data, Gobillon et al. (2010) find job-seekers living in cities in which the ZFU program was implemented do not exit unemployment faster than those living elsewhere. ${ }^{13}$ Their results are compatible with two explanations. First, at the city-level, the net impact of policy minus its spatial externalities may be too weak to be detected. Second, more jobs locally do not necessarily mean less job-seekers. According to the results of a survey conducted in 2008 targeting local authorities and some companies located in the ZFU areas, companies declare major difficulties to hire employees inside the area (and minor but not major difficulties to hire outside the area) in more than two third of these areas. This fact could question the efficiency of local tax exemptions as a tool to reduce local unemployment, especially in areas where workers lack basic skills. One possibility could be to combine place-based tax exemptions to increase labor demand with place-based training programs to improve the quality of local human capital.

Beside labor market aspects, the same survey reports that companies complained about the lack of land availability and more specifically of commercial real estates. A shortage in real-estate supply could also hamper the efficiency of the policy, as landlords, either by increasing sell prices or rents, may capture part of the money. Finally, the relative failure of

\footnotetext{
${ }^{13}$ Because of data constraints, they have to use the municipality as the geographical unit.
} 
the policy could be due to a lack of information about the policy or uncertainty about the local application of fiscal rules, as emphasized by the local survey. Some companies would, for instance, waive their rights to tax exemptions in order to avoid tax inspection. As shown by Kolko \& Neumark (2010), the way the areas are monitoring by zone administrators can make a difference in the final assessment of the policy. 


\section{References}

Bertrand, M., Duflo, E. \& Mullainathan, S. (2004), 'How much should we trust differencesin-differences estimates?', The Quarterly Journal of Economics 119, 249-275.

Bondonio, D. \& Engberg, J. (2000), 'Enterprise zones and local employment: Evidence from the states' programs', Regional Science and Urban Economics 30, 519-549.

Bondonio, D. \& Greenbaum, R. T. (2007), 'Do local taxes incentives affect economic growth? what mean impacts miss in the analysis of enterprise zones policies', Regional Science and Urban Economics 37, 121-136.

Busso, M. \& Kline, P. (2008), Do local economic development programs work? evidence from the federal empowerment zone program. Cowles Foundation Discussion Paper 1638.

Elvery, J. (2009), 'The impact of enterprise zones on residential employment: An evaluation of the enterprise zone programs of California and Florida', Economic Development Quarterly 23, 44-59.

Gobillon, L., Magnac, T. \& Selod, H. (2010), Do unemployed workers benefit from entreprise zones? CEPR Working Paper 8084.

Gobillon, L., Magnac, T. \& Selod, H. (2011), 'The effect of location on finding a job in the Paris region', Journal of Applied Econometrics .

Gobillon, L., Selod, H. \& Zenou, Y. (2007), 'The mechanisms of spatial mismatch', Urban Studies 44(12), 2401-2427.

Greenbaum, R. \& Bondonio, D. (2004), 'Losing focus: A comparative evaluation of spatially targeted economic revitalization programmes in the us and the eu', Regional Studies 38(3), 319-334.

Ham, J. C., Swenson, C., Imrohoroglu, A. \& Song, H. (2011), 'Government programs can improve local labor markets: Evidence from state enterprise zones, federal empowerment zones and federal enterprise community', Journal of Public Economics 95(7-8), 779 797.

Heckman, J., Ichimura, H., Smith, J. \& Todd, P. (1998), 'Characterizing selection bias using experimental data', Econometrica 66(5), 1017-1098.

Hellerstein, J. K. \& Neumark, D. (2011), Employment in black urban labor markets: Problems and solutions, NBER Working Papers 16986, National Bureau of Economic Research, Inc. 
Kolko, J. \& Neumark, D. (2010), 'Do some enterprise zones create jobs?', Journal of Policy Analysus and Management 29(1), 5-38.

Lynch, D. \& Zax, J. S. (2010), Incidence and substitution in enterprise zone programs: The case of Colorado. mimeo University of Colorado of Boulder.

Manning, A. \& Pischke, J.-S. (2006), Comprehensive versus selective schooling in England and Wales: What do we know? IZA DP 2072.

Neumark, D. \& Kolko, J. (2010), 'Do enterprise zones create jobs? evidence from California's enterprise zone program', Journal of Urban Economics.

O'Keefe, S. (2004), 'Job creation in California's enterprise zones: A comparison utilizing a propensity score matching model', Journal of Urban Economics 55, 131-150.

Papke, L. E. (1994), 'Tax policy and urban development: Evidence from the Indiana enterprise zone program', Journal of Public Economics 54, 37-49.

R Development Core Team (2010), R: A Language and Environment for Statistical Computing, , R Foundation for Statistical Computing, Vienna, Austria.

Rosenbaum, J. E. \& Zuberi, A. (2010), 'Comparing residential mobility programs: design elements, neighborhood placements, and outcomes in MTO and Gautreaux', Housing Policy Debate 20(1), 27-41.

Rosenbaum, P. R. \& Rubin, D. B. (1983), 'The central role of the propensity score in observational studies for causal effects', Biometrika 70, 41-55.

Åslund, O., Östh, J. \& Zenou, Y. (2010), 'How important is access to jobs? old question improved answer', Journal of Economic Geography 10(3), 389-422. 


\section{Appendix A: Tax exemptions in ZRU and ZFU}

According to the 2007 ONZUS report, companies in ZFU and ZRU benefit from the following tax exemptions :

Local business tax: only companies with less than 50 employees and a turnover of less than $€ 10$ million are concerned by ZFUs. Businesses located in ZFUs are fully exempt for five years, within the limit of a taxable amount of $€ 337,713$ (2006) and $€ 100,000$ of cumulated aid over 3 years. In ZRUs, all businesses with less than 150 employees are eligible. However, the ceiling of the taxable amount is lower: it amounted to $€ 125,197$ in 2006 .

Property tax on buildings: all buildings located in ZFUs belonging to companies liable for this tax are exempt for 5 years. ZRUs are not concerned.

Corporate income tax: companies located in ZFUs with less than 50 employees and a turnover of less than $€ 10$ million are exempt for 5 years, within the limit of $€ 100,000$ per year (increased by $€ 5,000$ per new recruit). In ZRUs, this exemption is limited to newly created companies in the area, with no staff limitations. These benefit from full exemption for 2 years and decreasing exemption for the next 3 . Corporate income tax exemption is limited to $€ 225,000$ per 36 -month period.

Employer contributions: companies located in ZFUs with less than 50 employees, a turnover of less than $€ 10$ million and one third of whose staff live in the ZUS where the ZFU is located are concerned. Employees with open-ended contracts or fixed-term employment contracts of more than 12 months are exempt from employer contributions for 5 years, on the fraction of salary lower than 1.4 times the minimum wage (Smic). This measure concerns companies with less than 50 employees in full-time equivalent and is limited to a cumulated $€ 100,000$ over 3 years. In ZRUs, there is no staff or turnover limitation for the company, but this exemption only relates to new recruits and lasts for 12 months (maximum of 50 jobs in full-time equivalent).

Furthermore, in ZFUs, the exemption from local business tax, corporate income tax and property tax is prolonged on a decreasing basis for 3 or 9 years, depending on whether the company has more or less than 5 employees. 


\section{Appendix B: Neighborhoods of ZFU}

Table 8 compares the economic situations in the 300-meter neighborhood rings built around ZFUs and untreated ZRUs.

Table 8: Economic situation in the rings surrounding ZFUs and ZRUs in 2002

\begin{tabular}{lcc} 
& \multicolumn{2}{c}{ 300-meter-wide rings around... } \\
& untreated ZRUs & ZFU \\
\hline Number of firms & 214 & 416 \\
Number of workers & 1887 & 5198 \\
Annual number of... & & \\
New firms & 30 & 59 \\
Creations & 23 & 44 \\
Transfers & 8 & 15 \\
Divided by the stock of the previous year & \\
New firms & 0.14 & 0.15 \\
Creations & 0.11 & 0.11 \\
Transfers & 0.03 & 0.04 \\
\hline Number of rings & 284 & 41 \\
\hline
\end{tabular}

